\title{
Brain-Derived Neurotrophic Factor Rescues Synaptic Plasticity in a Mouse Model of Fragile X Syndrome
}

\author{
Julie C. Lauterborn, ${ }^{1}$ Christopher S. Rex, ${ }^{2}$ Eniko Kramár, ${ }^{3}$ Lulu Y. Chen, ${ }^{1}$ Vijay Pandyarajan, ${ }^{1}$ Gary Lynch,,${ }^{3}$ and \\ Christine M. Gall ${ }^{1,2}$ \\ Departments of ${ }^{1}$ Anatomy and Neurobiology, ${ }^{2}$ Neurobiology and Behavior, and ${ }^{3}$ Psychiatry and Human Behavior, University of California, Irvine, \\ California 92697-4292
}

\begin{abstract}
Mice lacking expression of the fragile $\mathrm{X}$ mental retardation $1(F m r 1)$ gene have deficits in types of learning that are dependent on the hippocampus. Here, we report that long-term potentiation (LTP) elicited by threshold levels of theta burst afferent stimulation (TBS) is severely impaired in hippocampal field CA1 of young adult Fmr1 knock-out mice. The deficit was not associated with changes in postsynaptic responses to TBS, NMDA receptor activation, or levels of punctate glutamic acid decarboxylase-65/67 immunoreactivity. TBS-induced actin polymerization within dendritic spines was also normal. The LTP impairment was evident within 5 min of induction and, thus, may not be secondary to defects in activity-initiated protein synthesis. Protein levels for both brain-derived neurotrophic factor (BDNF), a neurotrophin that activates pathways involved in spine cytoskeletal reorganization, and its TrkB receptor were comparable between genotypes. BDNF infusion had no effect on baseline transmission or on postsynaptic responses to theta burst stimulation, but nonetheless fully restored LTP in slices from fragile X mice. These results indicate that the fragile X mutation produces a highly selective impairment to LTP, possibly at a step downstream of actin filament assembly, and suggest a means for overcoming this deficit. The possibility of a pharmacological therapy based on these results is discussed.
\end{abstract}

Key words: hippocampus; cofilin; actin; neurotrophin; LTP; mental retardation

\section{Introduction}

Fragile X syndrome (FXS), a common form of inherited mental retardation, is typically caused by an expansion of CGG-repeats in the gene [fragile X mental retardation $1(F m r 1)$ ] that encodes fragile X mental retardation protein (FMRP); expression of the gene is blocked, and the disease appears, when the number of repeats passes a threshold length $(\geq 200)$. The fragile $X$ protein associates with polyribosomes and functions as a negative regulator of protein synthesis (Todd and Malter, 2002) including that occurring in the vicinity of dendritic spines (Zalfa et al., 2003; Weiler et al., 2004; Muddashetty et al., 2007). Fmr1-knock-out (KO) mice, developed to model the disease, breed normally, generate full knock-out progeny, and exhibit impaired learning in the Morris water maze (The Dutch-Belgian Fragile X Consortium, 1994; Oostra and Hoogeveen, 1997). Although there are no gross brain abnormalities, adult knock-out mice have unusually long, thin spines in apical dendrites of neocortical and hippocampal pyramidal neurons (Comery et al., 1997; Irwin et al., 2002; Grossman et al., 2006). Similarly, abnormal spines have been

Received June 8, 2007; revised July 27, 2007; accepted Aug. 18, 2007.

This work was supported by National Institute of Neurological Disorders and Stroke Grants NS045260, NS051823, and NS37799, National Institute of Child Health and Human Development Grant HD51829, and University of California Discovery Grant bio05-10538 from the University of California Industry-University Cooperative Research Program. C.S.R. was supported by National Institute on Aging Training Grant AG00358. We thank Dr. Jihua Liu and Yue Qin Yao for expert technical assistance.

Correspondence should be addressed to Dr. Julie C. Lauterborn, Department of Anatomy and Neurobiology, University of California, Irvine, CA 92697-4292. E-mail: jclauter@uci.edu.

D01:10.1523/JNEUROSCI.2624-07.2007

Copyright $\odot 2007$ Society for Neuroscience 0270-6474/07/2710685-10\$15.00/0 observed in autopsy material from patients with FXS (Rudelli et al., 1985; Hinton et al., 1991; Irwin et al., 2001) or other forms of mental retardation (Marin-Padilla, 1972, 1974; Lund, 1978). These findings suggest that dendritic spines, and possibly the excitatory synapses associated with them, fail to fully mature in these conditions.

Long-term potentiation (LTP), a form of synaptic plasticity implicated in the encoding of memory (Cooke and Bliss, 2006), is accompanied by changes in the cytoskeletal organization and morphology of dendritic spines (Meng et al., 2003; Lin et al., 2005a; Carlisle and Kennedy, 2005). It is thus possible that spine abnormalities found in FXS disrupt the production of LTP and thereby produce learning problems that characterize the syndrome. However, although deficits in activity-dependent synaptic plasticity are reported for cingulate (Zhao et al., 2005) and somatosensory (Desai et al., 2006) cortices as well as for conventional LTP in somatosensory (Li et al., 2002) and piriform (Larson et al., 2005) cortices of Fmr1-KO mice, there is no evidence for an impairment in the hippocampus (Godfraind et al., 1996; Paradee et al., 1999; Li et al., 2002; Larson et al., 2005). As to mechanisms underlying the cortical impairments, Meredith et al. (2007) reported aberrant calcium signaling in dendrites and spines of Fmr1-KO prefrontal cortical neurons.

Previous studies have shown that the use of intense afferent stimulation to induce LTP can mask deficits that are evident when threshold, physiologically plausible conditions are used (Lynch et al., 2007a). As might be expected from this observation, treatment with agents known to promote the induction of LTP in 
normal tissue can reverse age- (Rex et al., 2006) or disease-related (Lynch et al., 2007b) disturbances found with threshold-levels of stimulation. The present studies were prompted by these findings and had three objectives: (1) to determine if hippocampal LTP is impaired in Fmr1-KOs at threshold levels of stimulation; (2) to identify the causes of any such deficits; (3) to test whether impairments can be reversed by brain-derived neurotrophic factor (BDNF), a potent endogenous modulator of the potentiation effect (Bramham and Messaoudi, 2005).

\section{Materials and Methods}

Electrophysiology. Transverse hippocampal slices $(350 \mu \mathrm{m})$ through the mid-septotemporal hippocampus were prepared with a vibratome (VT 1000 S; Leica, Bannockburn, IL) in ice-cold artificial CSF [ACSF; containing (in mM) $124 \mathrm{NaCl}, 3 \mathrm{KCl}, 1.25 \mathrm{KH}_{2} \mathrm{PO}_{4}, 3.4 \mathrm{CaCl}_{2}, 2.5 \mathrm{MgSO}_{4}, 26$ $\mathrm{NaHCO}_{3}$, and 10 dextrose, $\mathrm{pH} 7.35$ ) from young (2-3 months old) adult Fmr1-KO and wild-type (WT) mice (unless otherwise specified, chemicals were from Sigma, St. Louis, MO). Past work has shown that interface slices maintained in these cation concentrations reliably reproduce a broad array of physiological characteristics found in vivo and, in addition, exhibit excellent stability over hours of testing. Related to this, pharmacological results obtained with such slices accurately predict effects obtained with chronic recordings or biochemical assays from behaving animals (Staubli et al., 1994; Lauterborn et al., 2000), a point that is of importance to those aspects of the present work concerned with therapeutic strategies. All experiments were initiated between 9:00 and 11:00 A.M., and slices from Fmr1-KO and WT animals were randomized across two chambers and run simultaneously. Slices were maintained at $31 \pm 1^{\circ} \mathrm{C}$ in an interface recording chamber with the slice surface exposed to warm, humidified $95 \% \mathrm{O}_{2} / 5 \% \mathrm{CO}_{2}$ and continuous ACSF perfused at a rate of $60-70 \mathrm{ml} / \mathrm{h}$. Slices equilibrated to the chamber for at least $1 \mathrm{~h}$ before recordings were initiated. A single glass electrode $(2 \mathrm{M} \mathrm{NaCl})$ was placed within the mid proximodistal aspect of stratum radiatum in hippocampal field CA1b and was used to record field EPSPs (fEPSPs) from the apical dendrites of CA1 pyramidal cells. Orthodromic stimulation was delivered at two sites (CA1a and CA1c) in the apical Schaffer collateral-commissural projections to provide convergent activation of CA1b pyramidal cells. Pulses were administered in an alternating manner to the two electrodes at $0.05 \mathrm{~Hz}$ by using a current that elicited a $50 \%$ maximal response. Only after a stable baseline was achieved for a minimum of $10-15$ min were slices stimulated for response characterization. Inputoutput and paired-pulse facilitation assays were performed as described previously (Rex et al., 2005). Synaptic potentiation was induced with a train of 5 or 10 theta bursts (each containing four pulses at $100 \mathrm{~Hz}$, with an interburst interval of $200 \mathrm{~ms}$ ) (Larson et al., 1986; Kramár and Lynch, 2003; Rex et al., 2005). Evoked responses were digitized (NacGather 2.0; Theta Burst, Irvine, CA) and analyzed for amplitude and fall slope; data are presented as a percentage of baseline. Responses to individual theta bursts were analyzed to determine the burst area; to evaluate treatment effects on theta train facilitation, responses to each burst in the theta train are presented as a percentage change from the area of the initial burst response. Unless otherwise stated, group size values presented in the figures represent number of slices tested. Generally two to three slices were tested from a given mouse, and no fewer than three mice were used in any group; for statistical analyses, each slice was considered an individual $n$. Statistical significance was assessed using either two-way repeated-measures ANOVA to compare values that were stable over time or Mann-Whitney $U$ test to compare groups expressing different decay rates (i.e., values not stable over time); statistical analyses were performed using SPSS version 15.0 (SPSS, Chicago, IL.) Variance for physiology experiments is expressed as SEM.

A recirculating perfusion system (oxygenated and heated as above) with a peristaltic pump $(60 \mathrm{ml} / \mathrm{h}$; MasterFlex C/L; Cole-Parmer, Vernon Hills, IL) was used for experiments in which purified BDNF (catalog \#GFO29; Millipore, Temecula, CA) was administered to slices. The purity of the recombinant (mature) BDNF was confirmed using Western blot analyses: a single $14 \mathrm{kDa}$ band was observed under denaturing conditions (supplemental Fig. 1, available at www.jneurosci.org as supple- mental material). Slices received BDNF for $30 \mathrm{~min}$ to $1 \mathrm{~h}$ before physiological recording. BDNF stock was prepared in $\mathrm{ddH}_{2} \mathrm{O}$ at a concentration of $2 \mathrm{~nm}$ and stored at $-20^{\circ} \mathrm{C}$. Control slices from the same animals received ACSF alone in parallel on a second recirculating interface chamber. As a control for the specificity of the effect of BDNF, additional experiments were conducted in which slices from the same animal were treated with either BDNF or heat-inactivated BDNF; BDNF was heatinactivated by boiling for $5 \mathrm{~min}$ immediately before use.

In situ labeling of F-actin and quantification of dendritic spines. Forty minutes after theta burst afferent stimulation (TBS), AlexaFluor 568phalloidin $(6 \mu \mathrm{M}, 4 \mu \mathrm{l}$; Invitrogen, Carlsbad, CA) was topically applied via micropipette four times separated by $3 \mathrm{~min}$, and the tissue was then immediately fixed using $4 \%$ paraformaldehyde in $0.1 \mathrm{M}$ sodium phosphate buffer (PB), pH 7.2. The application of phalloidin after stable LTP precludes any possibility of disturbances to the induction and early expression of LTP (Rex et al., 2007). After overnight fixation, slices were cryoprotected with $20 \%$ sucrose in PB (1-2 h), sectioned at $20 \mu \mathrm{m}$ on a freezing microtome (parallel to broad slice face), mounted onto Superfrost Plus slides, and coverslipped with Vectashield (Vector Laboratories, Burlingame, CA).

Sections were examined using epifluorescence illumination on an Olympus (Center Valley, PA) AX70 photomicroscope and Optronics Microfire CCD camera with a $40 \times$ oil PlanApo objective (NA 1.0). Quantitative analyses were performed on three serial sections situated $20-80 \mu \mathrm{m}$ below the surface of the original slice. A series of $20-30$ high-resolution digital photomicrographs were taken at $0.2 \mu \mathrm{m}$ focal steps through each section (z-stacks). Camera exposure time was adjusted for each experiment so that approximately four to eight densely labeled spines could be visualized in the sample field of control slices. Images intended for comparison were then collected with the same illumination and exposure settings. $z$-stacks were collapsed into a single image by extended focal imaging (Microsuite FIVE; Soft Imaging Systems, Lakewood, $\mathrm{CO}$ ) converted to grayscale, and intensity levels were scaled equally across all images (Photoshop CS2 version 9; Adobe Systems, Mountain View, CA) to values determined for each experiment to visualize low-intensity labeling.

Labeled spine-like structures were measured and counted from a 550 $\mu \mathrm{m}^{2}$ sampling zone in proximal stratum radiatum between the two stimulating electrodes using in-house software described in detail previously (Lin et al., 2005b; Rex et al., 2007). Briefly, intensity thresholds ( 8 bits/ pixel) were applied to identify spine-like structures at varying levels of label intensity within a range that reliably counted spine-like puncta. Pixel values for each image were normalized to reduce the impact of background intensity differences across the image, binarized using each intensity threshold, and finally cleaned by "erosion" and "dilation" filtering (Jain, 1984). Spine counts from three serial sections were averaged to produce a representative value for each tissue slice (Rex et al., 2007). Counting was done blindly on batches of slices that had been sectioned and stained together. Digital images of objects included in the counts were overlaid semitransparently with the original photomicrographs to confirm that they were spines.

Phosphorylated-cofilin immunofluorescence. Standard electrophysiological recording and delivery of TBS was performed on acute hippocampal slices (see above). Slices were collected 5-7 min after TBS and fixed and sectioned as described above. Sections from both genotypes were simultaneously processed for immunostaining using rabbit anti-pcofilin antisera (1:100; catalog \#12866; Abcam, Cambridge, UK). Sections were incubated with antisera for $40 \mathrm{~h}$ in $\mathrm{PB}$ containing $4 \% \mathrm{BSA}$ and $0.3 \%$ Triton X-100 (PBT) at $4^{\circ} \mathrm{C}$. Slides were then rinsed in PB, incubated (1 h, room temperature) in AlexaFlour-594 anti-rabbit IgG (1:1000; Invitrogen) in PBT, rinsed again, and coverslipped with Vectashield (Vector Laboratories). Control sections were processed through all procedures with primary antisera omitted from the first incubation; no labeling was visualized under these conditions.

Laser scanning confocal microscopy was performed using the Bio-Rad Laboratories (Hercules, CA) Radiance 2000 Laser Scanning System as described previously (Chen et al., 2007). Optical sections (1.0 $\mu \mathrm{m})$ were scanned $(512 \times 512$ pixel format $)$ with a $60 \times$ objective $(1.4 \mathrm{NA})$ and magnified with $4 \times$ zoom. Image montages covering a $42,025 \mu \mathrm{m}^{2}$ area 
A.
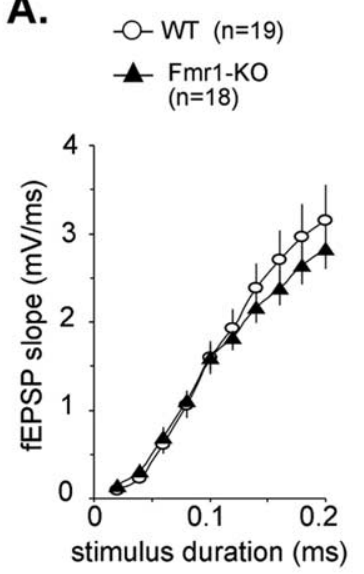

C.

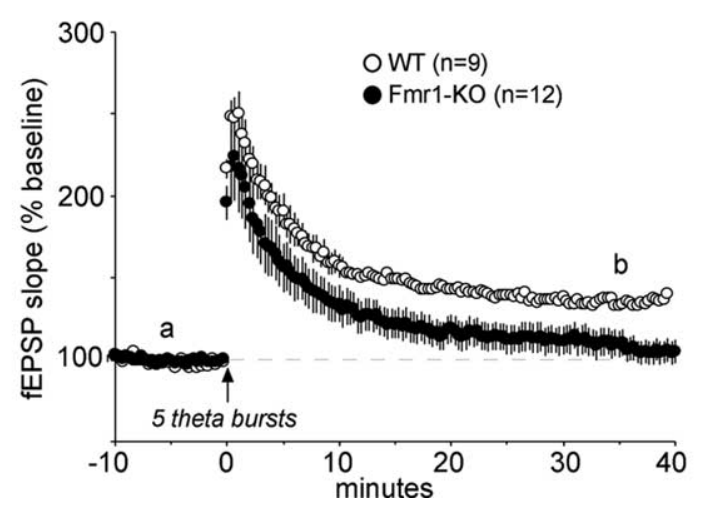

B. $\quad O W T(n=9)$

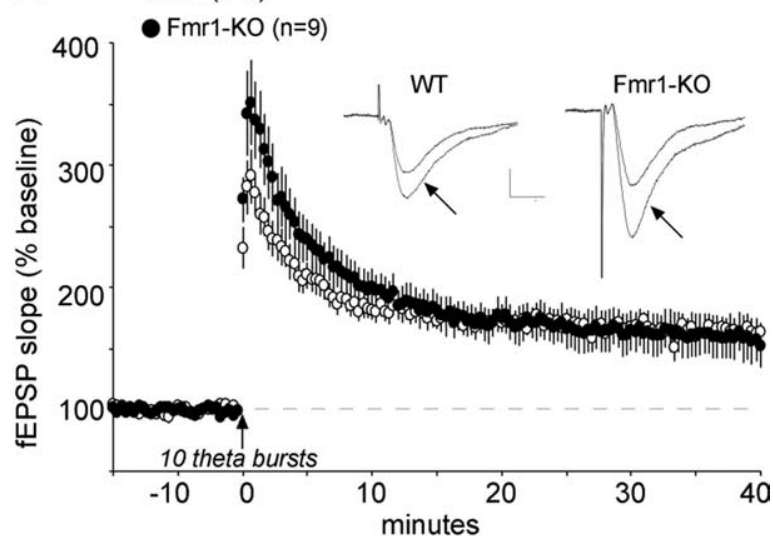

D.
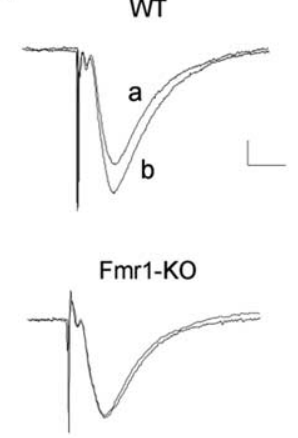

Figure 1. Hippocampal LTP is impaired in young adult Fmr1-KO mice. $A$, Plot of input-output curves generated from field responses to single pulse stimulation (duration increased in $0.02 \mathrm{~ms}$ steps) for Fmr 1 -KO (closed triangles) and WT (open circles) mice. $\boldsymbol{B}$, A single train of 10 theta bursts was delivered (arrow, time 0 ) to the apical branch of the Schaffer commissural projections and fEPSP responses to single pulses were collected from field CA1b for 40 min. Group data (mean \pm SEM) are expressed as the percentage of mean fEPSP slopes recorded during the baseline (pre-theta burst) period. There were no reliable differences between WT (open circles) and mutant (closed circles) slices. Inset, Overlaid representative fEPSP traces collected during baseline and for 35 min (arrows) post-TBS for WT and Fmr 1-KO mice. Calibration: $0.5 \mathrm{mV}, 10 \mathrm{~ms}$. C, Same as $\boldsymbol{B}$ except that the theta train contained only five bursts. Fmr1-KO slices (closed circles) expressed comparable initial potentiation to WTs, but the effect decayed rapidly to baseline by $30 \mathrm{~min}$. $\boldsymbol{D}$, Representative traces of fEPSPs for time points denoted in $C$ (a, baseline; $b$, 35 min post-TBS) for slices from WT and Fmr1-K0 mice. Calibration: $0.5 \mathrm{mV}, 10 \mathrm{~ms}$.

were collected from the zone between the two stimulation electrodes containing potentiated synapses. A sample field $\left(3,126 \mu \mathrm{m}^{2}\right)$ was converted to grayscale and intensity levels were scaled to values determined for each experiment (Photoshop CS, version 8.0; Adobe Systems) to visualize low-intensity labeling. Spine measurements were performed as described previously (Chen et al., 2007). Analysis was conducted blind on cohorts of slices from Fmrl-KOs and WTs that had been sectioned and stained together. Automatic spine identification and synapse area measurements were performed as described previously (Lin et al., 2005a; Chen et al., 2007) and above. Identified objects measuring $<0.04 \mu \mathrm{m}^{2}$ and $>1.2 \mu \mathrm{m}^{2}$ were excluded from analysis.

GAD Immunofluorescence. Young adult (2-3 months old) Frm1-KO and WT mice were perfused with $4 \%$ paraformaldehyde in $0.1 \mathrm{M} \mathrm{PB}, \mathrm{pH}$ 7.2 , and brains were processed for the immunocytochemical localization of glutamic acid decarboxylase (GAD) isoforms 65 and 67. Briefly, tissue was preincubated in $0.1 \mathrm{M} \mathrm{PB}$ containing $3 \%$ normal goat serum and $0.1 \%$ Triton-X for $1 \mathrm{~h}$ at room temperature. Tissue was then incubated with rabbit anti GAD-65/67 (catalog \#AB1511, Millipore) diluted 1:1000 in $0.1 \mathrm{M} \mathrm{PB}$ at $4^{\circ} \mathrm{C}$ for $48 \mathrm{~h}$, rinsed in $0.1 \mathrm{M} \mathrm{PB}$, and then incubated in AlexaFluor 488 anti-rabbit (1:1000; Invitrogen) at room temperature for $1 \mathrm{~h}$. After rinses in PB, tissue was mounted onto slides and coverslipped with Vectashield.

Widefield photomicrographs of GAD 65/67-immunolabeling in CA1 stratum radiatum were collected on a Leica (Bannockburn, IL) DM6000 B microscope using a $63 \times$ Plan Apo (1.4 NA) objective. $Z$-series $(0.2 \mu \mathrm{m}$ step $)$ images were deconvolved by iterative restoration using Volocity 4.0 Restoration software (Improvision, Lexington, MA). For each animal, GAD-immunoreactive puncta were counted from a $40,000 \mu^{3}$ sampling zone in proximal stratum radiatum in 10 adjacent tissue sections using in-house software as described above (see phalloidin analysis) with parameters set to identify puncta; analysis was conducted blind. Counts were then averaged to give an animal mean per $40,000 \mu \mathrm{m}^{3}$ (from a $1024 \times 1344 \times 3 \mu \mathrm{m}$ sample zone). Statistical significance was assessed by Student's $t$ test using GraphPad (San Diego, CA) Prism version 4.0.

Western blotting. Bilateral hippocampi were dissected and pooled for each animal $(n=6$ for each genotype). Tissue was homogenized in cold RIPA buffer (10 mm Tris, pH 7.2, $158 \mathrm{~mm}$ $\mathrm{NaCl}, 1 \mathrm{~mm}$ EDTA, $0.1 \%$ SDS, $1 \%$ sodium deoxycholate, $1 \%$ Triton-X, $1 \mathrm{~mm} \mathrm{Na}_{3} \mathrm{VO}_{4}$, and $1 \times$ complete protease inhibitor cocktail; Roche Diagnostics, Indianapolis, IN). Sample protein levels were measured (Bio-Rad Protein Assay) and volumes adjusted to normalize protein content. Proteins were then separated using $15 \%$ SDS PAGE $(25 \mu \mathrm{g} / \mathrm{lane})$, transferred to polyvinylidene difluoride membranes ( $\mathrm{Hy}$ bond-P; GE Healthcare Bio-Sciences, Piscataway, NJ), and processed for Western blot analysis of levels of BDNF and TrkB immunoreactivity using rabbit anti-BDNF that detects both precursor and mature BDNF $(\mathrm{N}-20$, cata$\log$ \#s.c.-546; Santa Cruz Biotechnology, Santa Cruz, CA) (Michalski and Fahnestock, 2003) and rabbit anti-TrkB (catalog \#T14930; Transduction Laboratories, Lexington KY). Briefly, membranes were blocked in 5\% nonfat dry milk, in Tris-buffered saline Tween 20 (TBST) for $1 \mathrm{~h}$ and then incubated in antisera diluted to 1:5000 for anti-BDNF or 1:2000 for anti TrkB in $5 \%$ milk/TBST for $2 \mathrm{~h}$ at room temperature. After $1 \mathrm{~h}$ incubation with HRP-conjugated anti-rabbit IgG (1:10,000; GE Healthcare BioSciences) in $5 \%$ milk/TBST, immunoreactive bands were visualized by enhanced chemiluminescence using ECL-Plus kit and reagents (GE Healthcare Bio-Sciences). To control for loading differences across lanes, membranes were stripped and reprobed for actin using mouse anti-actin diluted 1:200,000 (clone AC-15; Sigma) or tubulin using mouse anti- $\beta$ tubulin diluted 1:400,000 (catalog \#T4026; Sigma). Preliminary studies demonstrated that hippocampal whole homogenate levels of actin and tubulin immunoreactivities did not vary between WT and mutant mice (supplemental Fig. 2, available at www.jneurosci.org as supplemental material). Levels of immunoreactivity were assessed by densitometric analysis of films using the NIH Image 1.62 system; levels of BDNF and TrkB immunoreactivity were normalized to actin levels as assessed for the same Western blot lane. Statistical significance was determined by Student's $t$ test using GraphPad Prism version 4.0.

\section{Results}

Hippocampal slices were prepared from 2- to 3-month-old Fmr1-KO and WT mice. Input-output curves for fEPSP elicited in the CA1 region by stimulation of the Schaffer commissural projections were not detectably different between the two groups $(p>0.1$, repeated measures ANOVA) (Fig. $1 A)$. Potential geno- 
type differences in presynaptic release probability were assessed by paired pulse facilitation with 50,100, 150, and $200 \mathrm{~ms}$ interpulse intervals. The measure showed no effect of genotype $(p>0.35$ for all intervals; two-tailed t tests; $n=11$ and 10 for WT and Fmr1-KO, respectively). Past studies indicate that a train of 10 theta bursts is well above threshold and induces a near maximal degree of LTP in field CA1; that is, adding more bursts, or pulses to individual bursts, does not substantially affect the percentage potentiation obtained (Larson et al., 1986; Kramár et al., 2004). As shown in Figure $1 B$, a single train of 10 theta bursts produced a $>50 \%$ increase in the slope of fEPSPs with no evident differences between WT and mutant mice $(p>0.5$, two-way repeatedmeasures ANOVA for minutes 30-40). This confirms previous reports using different stimulation paradigms that the machinery for generating LTP in hippocampus is present in Fmrl-KO mice (Godfraind et al., 1996; Li et al., 2002). However, a different result was obtained with five theta bursts (Fig. 1C): LTP in the wild types $(+35.3 \pm 2.3 \%$, mean \pm SEM at 35-40 min after TBS) was only slightly reduced from that found with the longer trains, whereas LTP in the mutants rapidly decayed to baseline $(+7.1 \pm 7.6 \%)$. The difference between WT and Fmrl-KO slices was highly significant $(p=0.012$, two-way repeated measures ANOVA for minutes 30-40). Examination of Fmr1-KO responses immediately after stimulation demonstrated that initial potentiation was comparable to that in the WTs. Significant group differences were evident by $5 \mathrm{~min}$ post stimulation $(+93.1 \pm 9.8 \%$ for WTs vs $43.0 \pm 11.6 \%$ for the KOs; $p=0.011)$. It is likely, then, that the mutation disrupted aspects of LTP production that occur in advance of activity-driven protein synthesis thought to subserve late LTP (Reymann and Frey, 2007).

We next attempted to identify which of the steps in LTP production were negatively affected by the mutation. There were no evident between-group differences in the waveforms of the composite postsynaptic responses (four overlapping field EPSPs) generated by theta bursts, as can be seen from the averaged traces in Figure $2 \mathrm{~A}$. The mean sizes of the initial burst responses in the train of five were comparable for WT cases $(+64.6 \pm 2.5 \mathrm{mV} \cdot \mathrm{ms})$ and mutants $(+60.5 \pm 5.9 \mathrm{mV} \cdot \mathrm{ms})$, as was the degree to which the burst responses facilitated during the trains. Figure $2 B$ describes the size (area) of burst responses two through five as a fraction of the size of the first burst in the train. The mean percent facilitation across burst responses $2-5$ was $+82.1 \pm 9.0 \%$ (median, +78 ) for the WT slices and $+70.0 \pm 10.7 \%$ (median, +82 ) for the Fmr1KOs. Estimates of the extent to which TBS engaged NMDA re- ceptors in the mutants were made by comparing burst responses in the presence and absence of the selective antagonist APV. As shown in Figure $2 C$, the antagonist caused a marked, and reversible, depression of the response to the second of two theta bursts. This is consistent with earlier work showing that feedforward IPSPs, once having been activated by an initial burst, enter a refractory period that has its peak near the onset time of a second theta burst (Larson and Lynch, 1986). This reduces the GABAergic conductance that normally shunts AMPA receptor-mediated excitation, and thereby reduces the prolonged depolarization needed to unblock NMDA receptors. The results summarized in 
Figure $2 C$ indicate that all of these processes are operational in Fmr1-KO mice.

The finding that burst responses were of comparable size, and increased by the same increment, across burst 1 to burst 2 in a theta train indicates that $\mathrm{GABA}_{\mathrm{A}}$ receptor mediated IPSPs, as well as the afterhyperpolarizations that follow cell spiking, are not significantly different between genotypes. To further assess the representation of GABAergic elements between genotypes, tissue sections from WT and Fmr1-KO mice were processed for the immunocytochemical localization of the GABA biosynthetic enzyme GAD using antisera that detects both the 65 and $67 \mathrm{kDa}$ isoforms, and immunolabeled puncta within the proximal stratum radiatum were counted. Quantification of both numbers and labeling densities of GAD-immunoreactive puncta revealed no differences between genotypes for these measures (supplemental Fig. 3, available at www.jneurosci.org as supplemental material).

Actin polymerization in dendritic spines is an essential step in the stabilization of TBS-induced LTP in rats (Fukazawa et al., 2003; Lin et al., 2005a; Kramár et al., 2006) and mice (Lynch et al., 2007b). Previous studies have shown that theta stimulation activates the $\mathrm{p} 21$-activated kinase (PAK)/cofilin pathway, which regulates the growth of actin filaments in dendritic spines (Chen et al., 2007; Rex et al., 2007). Phosphorylation inhibits the activity of cofilin, an actin-depolymerizing factor, and thus promotes actin polymerization. We tested whether this signaling pathway was engaged by TBS in the fragile X mutant. Hippocampal slices from WT and Fmr1-KO mice received five theta bursts and were left in the chamber for $7 \mathrm{~min}$, a time point at which the phosphorylation of cofilin is maximal after TBS in rat (Chen et al., 2007; Rex et al., 2007). Slices were then fixed and processed for the localization of phosphorylated ( $\mathrm{p}-$ ) cofilin using immunofluorescence techniques. As shown in the photomicrographs of Figure 3, p-cofilinimmunoreactive puncta were more numerous in stratum radiatum of CA1 in slices receiving TBS than in those receiving lowfrequency control stimulation. Quantification indicated that basal numbers were not significantly different between genotypes ( $p=0.32$ for low-frequency stimulation groups, Student's $t$ test), and that TBS resulted in significant increases in labeled puncta for both WT and Fmr1-KO mice ( $p=0.0019$ for WT control vs TBS groups, Student's $t$ test; $p=0.033$ for Fmr1-KO control versus TBS groups, Student's $t$ test). Moreover, the effect of stimulation was similar between genotypes ( $p=0.323$ for WT and Fmr1-KO TBS groups). These data indicate that the PAK/cofilin pathway is not perturbed in the mutant.

Next, we tested whether a deficit in actin polymerization might account for the rapid decay of potentiation in the Fmr1-KO mice. Alexa-568-labeled phalloidin was applied to slices beginning $30 \mathrm{~min}$ after delivery of five theta bursts to each of two converging populations of Schaffer-commissural afferents to the target field in CA1b stratum radiatum. The tissue was then fixed, sectioned, and examined under epifluorescence illumination. Figure $4 A$ shows representative photomicrographs from WT and Fmr1-KO slices. TBS produced a marked increase in the number of densely labeled puncta localized in the proximal stratum radiatum, the dendritic zone containing the stimulated synapses. Close examination indicated that the labeled structures had the size and appearance of dendritic spines. Quantification of intensely phalloidin-labeled spines demonstrated that both genotypes expressed low basal numbers in control slices receiving baseline low-frequency stimulation (Fig. $4 B)(11 \pm 2$ vs $5 \pm 1$, mean \pm SEM, per $550 \mu \mathrm{m}^{2}$ for WT vs Fmr1-KO). TBS-treated slices from fragile $\mathrm{X}$ mutants showed dramatically elevated num-
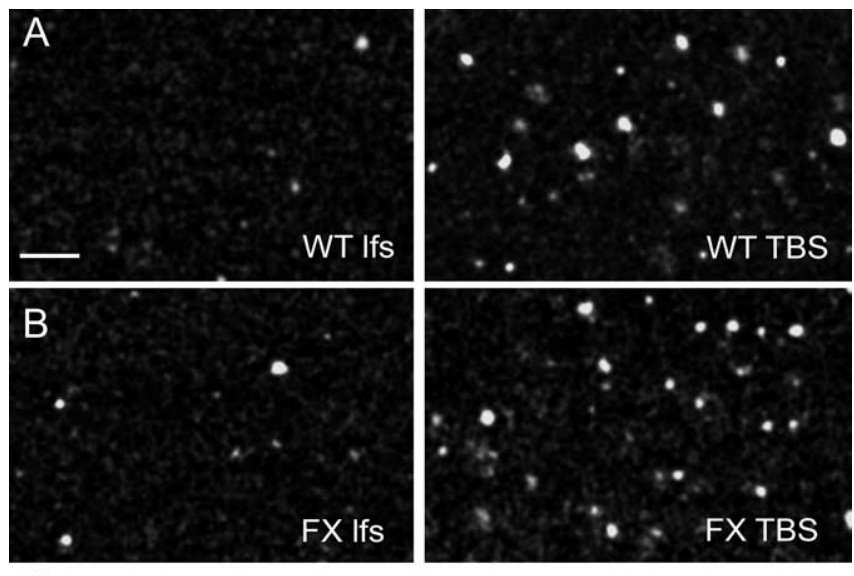

C
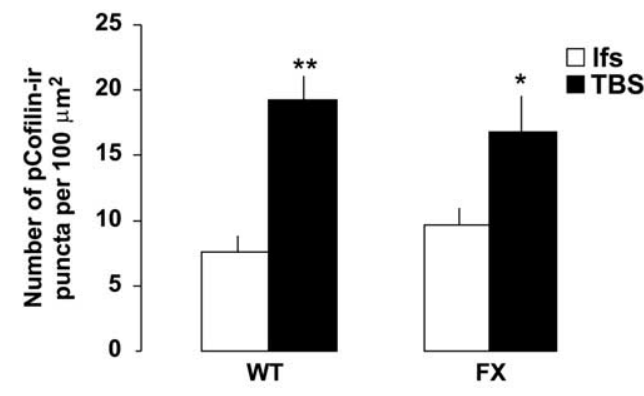

Figure 3. TBS-induced p-cofilin immunoreactivity is normal in Fmr1-KOs. $\boldsymbol{A}, \boldsymbol{B}$, Laser confocal photomicrographs show p-cofilin-immunoreactivity in proximal CA1 stratum radiatum of hippocampal slices from WT $(\boldsymbol{A})$ and Fmr1-KO (FX; $\boldsymbol{B})$ mice that received either baseline lowfrequency stimulation (Ifs) or five TBSs; slices were collected 7 min after stimulation. Scale bar, $1 \mu \mathrm{m}$. C, Bar graph shows the number of p-cofilin-immunoreactive (ir) puncta (mean $\pm \mathrm{SEM}$ ) per $100 \mu \mathrm{m}^{2}$ for fields receiving Ifs (open bars) or TBS (closed bars) in WT and Fmr1-K0 slices. Two-way ANOVA demonstrated a significant effect of TBS ( $p=0.00096)$, but no effect of genotype on $p$-cofilin-ir puncta counts. Thus, numbers of $p$-cofilin-ir puncta were significantly greater in slices that received TBS than in those that received Ifs for both WTs $\left({ }^{* *} p=0.0019, t\right.$ test; Ifs, $n=3$ mice; TBS, $n=3$ mice) and Fmr 1-KOs ( ${ }^{*} p=0.033, t$ test; Ifs, $n=3$ mice; TBS, $n=3$ mice).

bers of labeled spines $\left(36 \pm 10 / 550 \mu \mathrm{m}^{2}\right)$ versus unstimulated slices $[p<0.01$, Tukey honestly significant difference (HSD)]; the theta induced increases in labeled spines were not statistically different from values obtained for the TBS-treated WT slices $(40 \pm 5 ; p>0.3$, ANOVA). Mean values obtained for WT and Fmr1-KO slices receiving 10 theta bursts showed no additional elevations from the five burst cases (data not shown), consistent with previous findings in rats (Kramár et al., 2006). Finally, although spine morphology was not formally assessed in this material, a range of spine types and sizes was observed in both genotypes as shown in Figure 4C. Overall, these results suggest that TBS-induced actin polymerization, which normally accompanies synaptic potentiation, remains functional in the Fmr1-Kos, despite impairments in LTP.

The above results indicate that the complex machinery that induces, expresses, and begins the process of consolidating LTP is intact in the fragile $\mathrm{X}$ mutant mouse and is set in motion by five bursts of theta stimulation. However, it appears that some step in addition to or occurring beyond polymerization does not receive sufficient drive, in the five burst case, for activation, resulting in a potentiation that gradually decays. This raises the experimental question of whether increased levels of positive modulation can be used to enhance the effects of the near-threshold level of theta stimulation. We explored this possibility using BDNF, a neurotrophin that is released by theta burst stimulation (Balkowiec and 
Katz, 2002; Aicardi et al., 2004), potently promotes LTP in rat brain slices (Figurov et al., 1996; Chen et al., 1999; Kramár et al., 2004) and regulates plasticity-associated spine actin polymerization (Rex et al., 2007). Figure 5 summarizes results from experiments in which BDNF (2 $\mathrm{nm}$ ) was bath applied to WT or Fmr1-KO slices continuously through a recirculating perfusion system. In WT slices treated with BDNF, the delivery of five theta bursts produced potentiation $(+51.3 \pm 8.6 \%$ for minutes $30-40$ post-TBS) (Fig. $5 A$ ) that was similar to that elicited by five theta bursts in the absence of exogenous BDNF ( $p>0.5$ vs ACSF at 30-40 min; repeatedmeasures ANOVA) (compare Fig. 1C). This result accords with other reports (Pang et al., 2004; Lynch et al., 2007b) that, in marked contrast to results obtained with rat slices, the magnitude of LTP in wild-type mice is not elevated by low concentrations of BDNF. Fmr1-KO slices bathed in BDNF exhibited a degree of LTP $(+42.1 \pm 8.6 \%$ for minutes $30-40)$ (Fig. $5 A, B)$ that was equivalent to that in the WT slices, and was substantially greater than potentiation in mutant slices infused with either ACSF alone $(p=0.009$ for minutes $30-40$ post-TBS) or with ACSF containing heat-inactivated BDNF $(p<$ 0.05 ) (Fig. $5 B$ ). BDNF did not measurably affect facilitation of burst responses during the theta trains in either WT $(p>0.4)$ or Fmr1-KO mice $(p>0.4$ vs ACSF and heat-inactivated BDNF, two-way repeated measures ANOVA); Figure 5, $D$ and $E$, shows comparison of ACSF and BDNF effects in mutant slices for these measures. This again stands in marked contrast to results obtained with rat slices. Finally, BDNF did not alter input-output curves compared with slices infused with ACSF alone ( $p>0.3$ for both WT and Fmrl-KO, respectively) (data not shown) or with $2 \mathrm{~nm}$ heat-inactivated $\mathrm{BDNF}(p>0.3$ for Fmr1-KO) (Fig. 5C). It thus appears that BDNF selectively corrected the impairment to LTP consolidation in the mutants.

The restorative effects of BDNF in Fmr1-KO slices suggest the possibility that the synaptic deficits seen in these mice arise from impaired production of the neurotrophin. Accordingly, we compared levels of precursor and mature BDNF (14 kDa form) in hippocampus of Fmr1-KOs and WTs with Western blots (Fig. $6 A)$. In homogenates from WT and Fmrl-KO mice, there were several precursor forms of BDNF immunoreactivity ranging from 40 to $20 \mathrm{kDa}$, with two major bands at 32 and $20 \mathrm{kDa}$. Whereas non-neuronal cells transfected to over express proBDNF (Mowla et al., 2001) generate a major band of immunoreactivity at $32 \mathrm{kDa}$, other studies have identified BDNF precursors in the range of $30-38 \mathrm{kDa}$, and smaller proteolytic fragments ranging from 17 to $28 \mathrm{kDa}$ (Biagini et al., 2001; Mowla et al., 2001; Pang et al., 2004; Zhou et al., 2004b; Pollak et al., 2005; Teng et al., 2005). Therefore, to include the various pro-BDNF forms present in situ, we analyzed all bands from 20 to $40 \mathrm{kDa}$ in addition to mature BDNF. Levels of immunoreactivity were normalized to actin that served as a loading control; parallel analyses demonstrated that whole homogenate actin levels were not significantly different between genotypes $(p=0.8)$ (supplemental Fig. $2 A$, available at www.jneurosci.org as supplemental material). As shown in Figure $6 B$, concentrations of pro-BDNF and matureBDNF immunoreactivity were not statistically different between genotypes ( $p>0.05$ for WT versus KO, for all bands evaluated). These data indicate that expression and post-translational processing of BDNF are not disturbed in the hippocampus of the fragile X mutant mouse. Finally, total levels of BDNF's TrkB receptor were assessed by Western blotting in the same samples analyzed for BDNF content. Quantification of both full-length and truncated isoforms (145 and $95 \mathrm{kDa}$, respectively) identified no difference in TrkB levels between genotypes (supplemental Fig. $2 B$, available at www.jneurosci.org as supplemental material). Although these data indicate that the fragile $\mathrm{X}$ mutation does not affect total BDNF and TrkB levels, the possibility of more discrete (i.e., region-specific) alterations remains to be determined.

\section{Discussion}

Several factors and experimental conditions have been identified that modulate, but are not obligatory for, the induction and/or stabilization of LTP. BDNF, for example, is necessary for production of LTP by theta bursts, but is not required when long trains of high-frequency stimulation are used (Chen et al., 1999). Similarly, deficits in LTP in the aged hippocampus that are seen with modest stimulation protocols can be overcome by more intense afferent stimulation (Tombaugh et al., 2002). The defect related to the fragile $\mathrm{X}$ mutation also appears to involve a factor that contributes to, but is not essential for, the development of stable potentiation. Conventional 10 burst theta trains produced a normal-appearing LTP in mutant slices, whereas that elicited by a threshold number of bursts (Arai and Lynch, 1992) was markedly impaired. Notably, the threshold five burst trains more closely 
A.

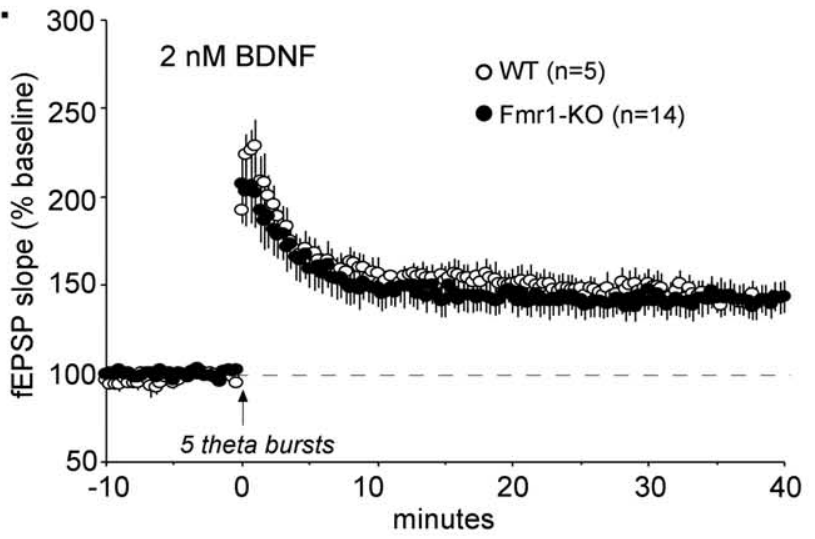

B.

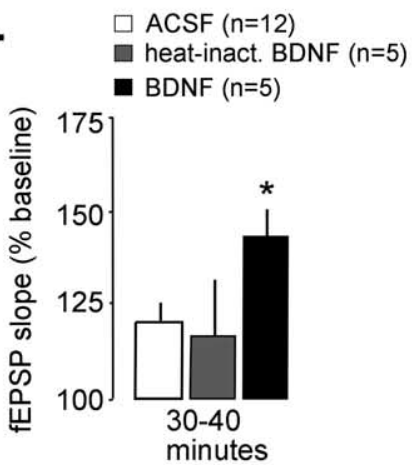

C. -0 heat-inactivated $\operatorname{BDNF}(n=8)$

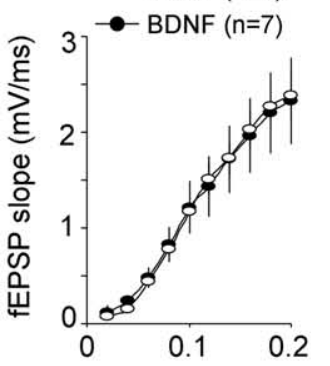
stimulus duration (ms)

D.

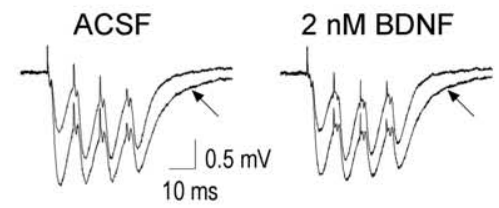

E.

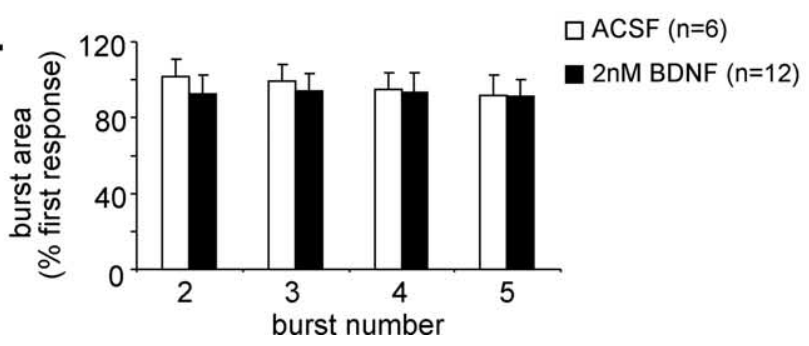

Figure 5. BDNF corrects the LTP deficit in fragile $X$ hippocampus. $A$, Five theta bursts were delivered to the Schaffer commissural projections in WT and Fmr1-KO slices that had been treated with BDNF ( $2 \mathrm{~nm}$ ) beginning 30 min before theta stimulation. Potentiation in the mutants did not decay rapidly toward baseline, as observed in untreated slices (Fig. 1C), and did not differ in magnitude from the effect obtained in BDNF-treated WT slices. $\boldsymbol{B}$, Mean fEPSP slope (average of $30-40 \mathrm{~min}$ post-TBS) expressed as a percentage of the last $10 \mathrm{~min}$ of baseline from Fmr1-KO slices either untreated (ACSF alone) or treated with BDNF or heat-inactivated BDNF. BDNF enhanced TBS-induced increases in the fEPSP slope compared with measures from the ACSF group $\left({ }^{*} p=0.009\right)$, whereas heat-inactivated BDNF had no effect. $C$, Group inputoutput data from Fmr1-KO slices treated with BDNF and heat-inactivated BDNF showed no effect of BDNF on fEPSP amplitude. $D$, Averaged responses to the first and fourth (arrow) theta bursts recorded from Fmr1-KO slices infused with BDNF or with ACSF only. As shown, the response waveforms were comparable between the two groups. $\boldsymbol{E}$, The effect of BDNF on burst response facilitation within a theta train in slices from fragile $X$ mutant mice was estimated by expressing the area of responses $2-5$ as a fraction of the first burst response. The mean degree of facilitation was similar in Fmr1-K0 slices treated with BDNF and those bathed in ACSF alone.

approximate conditions likely to occur in vivo than do full-length trains. Chronic recording studies have shown that a pattern similar to theta bursting occurs in hippocampus during learning, and

A.

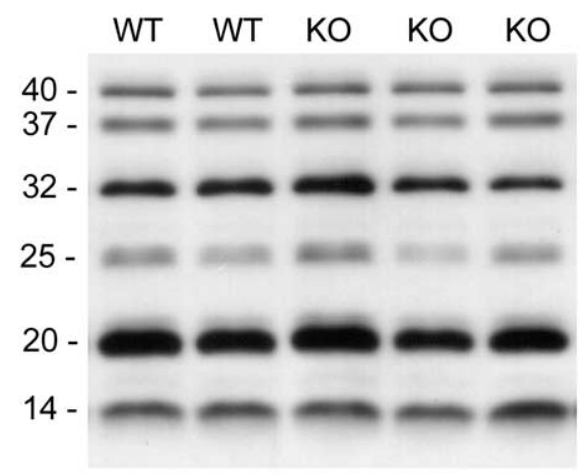

B.

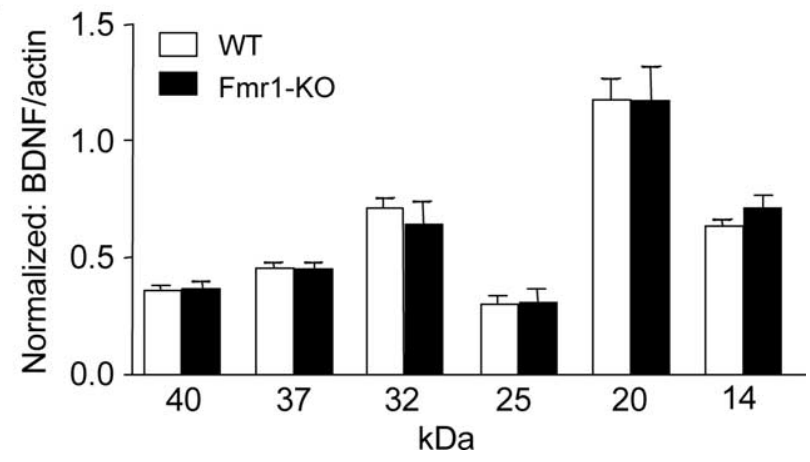

Figure 6. Hippocampal BDNF levels are normal in Fmr1-K0 mice. A, Representative Western blot showing pro-BDNF $(40-20 \mathrm{kDa}$ ) and mature BDNF (14 kDa) bands in hippocampal homogenates from WT and Fmr1-KO mice; band sizes (in kilodaltons) are indicated on the left. $\boldsymbol{B}$, Bar graph showing quantification of hippocampal BDNF bands ranging in mass from 14 to $40 \mathrm{kDa}$ for samples from WTs and Fmr 1 -KOs ( $n=6$ per genotype). Plot shows BDNF band densities normalized to actin levels for the same sample. For each band, protein levels were equivalent between genotypes.

that this typically involves small numbers of serial bursts (e.g., individual cells tend to fire in series of three to four bursts at theta frequency) (Otto et al., 1991). Such short trains are at threshold for producing LTP, although they can, with repetition over several minutes, incrementally produce full strength potentiation (Larson et al., 1986; Larson and Lynch, 1989; Colgin et al., 2003). In all, then, the fragile $\mathrm{X}$ impairment described here can reasonably be assumed to emerge as a plasticity deficit during learning and, thus, could be an important component in the behavioral aspects of the disease.

Possibly related to these observations, Meredith et al. (2007) reported previously that deficits in spike timing potentiation in the frontal cortex of Fmr1-KOs are only evident with threshold levels of stimulation and can be overcome with stronger stimulation.

Several LTP-related physiological variables known to be sensitive to experimental manipulation were not affected by the mutation. The theta burst response, which is shaped by a complex set of presynaptic and postsynaptic variables (Arai and Lynch, 1992; Lynch et al., 2007b), was by appearance and measurement not different between WTs and Fmr1-KOs. The facilitation of these composite responses over the course of a theta train, an event that involves suppression of inhibitory transmission via activation of GABA autoreceptors (Larson et al., 1986; Mott and Lewis, 1991), was similarly normal in the mutants. Moreover, the NMDA receptor-mediated component of the burst response (Larson and Lynch, 1998) and its facilitation during the theta train was present in the mutants and not evidently different in size or waveform from what is found in WT slices. These results point to a process 
other than initial induction as the element in LTP production that is affected by the fragile X mutation.

FMRP binds to mRNA as part of a ribonucleoprotein complex, but little is known regarding the proteins affected by its activity (Zalfa et al., 2003, 2007). There is, however, evidence that actin dynamics are sensitive to the fragile X mutation. Changes in the actin cytoskeleton produced by an extracellular signal, and mediated by the small GTPase Rac, are distorted in murine fibroblasts from fragile X mutants. Levels of phosphorylated (inactivated) cofilin, a protein that plays a key role in regulating the assembly of actin filaments, are abnormally low in these preparations, whereas concentrations of cofilin phosphatase are elevated (Castets et al., 2005). It is also the case that FMRP in Drosophila negatively regulates expression of the profilin homolog, a protein critical to the elongation of actin filaments (Reeve et al., 2005). The above proteins, along with actin itself, are enriched in dendritic spines (Racz and Weinberg, 2006; Chen et al., 2007), and perturbations to their activities could explain the abnormal spine morphologies associated with FXS. Disturbances to actin dynamics are also relevant to the observed deficits in LTP. Results from a series of electron microscopic studies indicate that rapid changes in the morphology of dendritic spines and their postsynaptic densities occur in conjunction with LTP (Lee et al., 1980; Desmond and Levy, 1986; Toni et al., 2001; Park et al., 2006); experiments with new light-microscopic techniques have confirmed changes in spine shape (Zhou et al., 2004a; Ehrlich et al., 2007) and increases in the size of the synapse (Chen et al., 2007). Other work indicates that theta bursts cause a rapid $(<2 \mathrm{~min})$ polymerization of actin in spine heads (Lin et al., 2005a), something that is a very likely prerequisite to shape change. The threshold for this effect is the same as that for induction of LTP, and treatments that block theta-induced polymerization, even if applied after the stimulation bursts, reverse LTP (Kramár et al., 2006). Given these points, a reasonable explanation for the loss of LTP (at threshold stimulation levels) would be that the FXS mutation depressed signaling pathways needed to modify spine morphology. However, even modest theta trains produced robust and normal-appearing increases in spine p-cofilin and F-actin levels in the mutant slices. Together with the results from the analysis of burst responses, these findings indicate that the LTP machinery, in Fmr1-KOs, is intact from the relatively brief physiological events required for induction through the complex signaling cascades needed for actin polymerization.

Given the above conclusion, it seems reasonable to look beyond actin assembly for the cellular defect that impairs LTP in fragile X mice. Work showing that theta-induced polymerization can be reversed in the first few minutes after its occurrence (Kramár et al., 2006) suggests that cross-linking, capping, and other activities that stabilize the cytoskeleton play a major role in LTP consolidation. Proteins involved in actin cross-linking, including spectrin (Siman et al., 1987; Walsh and Kuruc, 1992), adducin (Wyneken et al., 2001), actinin (Wyszynski et al., 1998), dystrophin (Jancsik and Hajos, 1998) and others, are concentrated in spines and/or postsynaptic densities. Of these proteins, at least one has been identified as potentially being regulated by FMRP: Antibody-positioned RNA amplification indicates that spectrin ( $\alpha$-fodrin) mRNA is among the RNA cargo of FMRP (Miyashiro et al., 2003). Moreover, although the LTP deficit in the mutants emerged before time points typically considered dependent on protein synthesis, there is evidence that under some stimulation conditions, local translation contributes to early processes of LTP stabilization (Woo and Nguyen, 2003; Kelleher et al., 2004). Together, these results raise the possibility that the FMRP mutation disrupts availability of locally translated actin cross-linking proteins and, consequently, cytoskeletal stabilization. Alternatively, the neuronal actin cytoskeleton is sensitive to calcium (Rosenmund and Westbrook, 1993; Furukawa et al., 1995) and there is indirect evidence that regulation of the cation is disturbed in cortex of fragile X mice (Meredith et al., 2007). Whatever their origins, the cytoskeletal problems found in the mutants appear to be partial because longer trains of afferent stimulation can overcome them to produce stable potentiation.

The evidence that the hippocampal LTP deficits in fragile X are both discrete and partial encourages the idea that they might be offset with one or more physiologically plausible treatments. BDNF acts via Rho GTPases to regulate the assembly of the actin cytoskeleton in developing neurons (Ozdinler and Erzurumlu, 2001; Gehler et al., 2004; Miyamoto et al., 2006), and there is previous evidence that aspects of these signaling pathways are retained into adulthood in hippocampus (Rex et al., 2007). These observations point to BDNF as a logical candidate for a treatment to offset the problems in spine reorganization hypothesized to arise from the fragile $\mathrm{X}$ mutation. The neurotrophin positively modulates the formation of LTP in normal rodents (Korte et al., 1995; Patterson et al., 1996; Kang et al., 1997), and is found to offset deficits in LTP in murine models of Huntington's disease (Lynch et al., 2007b), possibly via effects on the actin cytoskeleton (Rex et al., 2007). Consistent with these points, we found that brief infusions of $2 \mathrm{nM}$ BDNF fully restored LTP in Fmr1-KOs and did so without causing evident changes to baseline physiology or theta burst responses.

The latter results raise the question of whether it will be possible to treat the plasticity deficits in FXS by upregulating expression of BDNF. An approach of this type, using positive modulators of AMPA-type glutamate receptors to stimulate neurotrophin production, was reported previously to reverse age-related impairments to LTP in rat (Rex et al., 2006). Because BDNF protein has a relatively long half-life (Nawa et al., 1995; Sano et al., 1996), it was possible in those studies to stably increase neurotrophin levels using twice a day treatments with a short half-life compound (Rex et al., 2006). Given that the loss of FMRP does not appear to affect mature BDNF protein levels or processing, or levels of its high-affinity receptor TrkB, efforts to increase its production have a reasonable chance of being successful. This point supports the idea of using activity modulation and an endogenous BDNF-based strategy for the treatment of mental retardation in fragile $\mathrm{X}$ syndrome.

\section{References}

Aicardi G, Argilli E, Cappello S, Santi S, Riccio M, Thoenen H, Canossa M (2004) Induction of long-term potentiation and depression is reflected by corresponding changes in secretion of endogenous brain-derived neurotrophic factor. Proc Natl Acad Sci USA 101:15788-15792.

Arai A, Lynch G (1992) Factors regulating the magnitude of long-term potentiation induced by theta pattern stimulation. Brain Res 598:173-184.

Balkowiec A, Katz D (2002) Cellular mechanisms regulating activitydependent release of native brain-derived neurotrophic factor from hippocampal neurons. J Neurosci 22:10399-10407.

Biagini G, Avoli M, Marcinkiewicz J, Marcinkiewicz M (2001) Brainderived neurotrophic factor superinduction parallels anti-epileptic-neuroprotective treatment in the pilocarpine epilepsy model. J Neurochem 76:1814-1822.

Bramham C, Messaoudi E (2005) BDNF function in adult synaptic plasticity: the synaptic consolidation hypothesis. Prog Neurobiol 76:99-125.

Carlisle H, Kennedy M (2005) Spine architecture and synaptic plasticity. Trends Neurosci 28:182-187.

Castets M, Schaeffer C, Bechara E, Schenck A, Khandjian E, Luche S, Moine H, Rabilloud T, Mandel J, Bardoni B (2005) FMRP interferes with the 
Racl pathway and controls actin cytoskeleton dynamics in murine fibroblasts. Hum Mol Genet 14:835-844.

Chen G, Kolbeck R, Barde YA, Bonhoeffer T, Kossel A (1999) Relative contribution of endogenous neurotrophins in hippocampal long-term potentiation. J Neurosci 19:7983-7990.

Chen LY, Rex CS, Casale M, Gall CM, Lynch G (2007) Changes in synaptic morphology accompany actin aignaling during LTP. J Neurosci 27:5363-5372.

Colgin L, Kubota D, Lynch G (2003) Cholinergic plasticity in the hippocampus. Proc Natl Acad Sci USA 100:2872-2877.

Comery T, Harris J, Willems P, Oostra B, Irwin S, Weiler I, Greenough W (1997) Abnormal dendritic spines in fragile X knock-out mice: maturation and pruning deficits. Proc Natl Acad Sci USA 94:5401-5404.

Cooke S, Bliss T (2006) Plasticity in the human central nervous system. Brain 129:1659-1673.

Desai N, Casimiro T, Gruber S, Vanderklish P (2006) Early postnatal plasticity in neocortex of Fmr1 knockout mice. J Neurophysiol 96:1734-1745.

Desmond N, Levy W (1986) Changes in the postsynaptic density with longterm potentiation in the dentate gyrus. J Comp Neurol 253:476-482.

Ehrlich I, Klein M, Rumpel S, Malinow R (2007) PSD-95 is required for activity-driven synapse stabilization. Proc Natl Acad Sci USA 104:4176-4178.

Figurov A, Pozzo-Miller LD, Olafsson P, Wang T, Lu B (1996) Regulation of synaptic responses to high-frequency stimulation and LTP by neurotrophins in the hippocampus. Nature 381:706-709.

Fukazawa Y, Saitoh Y, Ozawa F, Ohta Y, Mizuno K, Inokuchi K (2003) Hippocampal LTP is accompanied by enhanced F-actin content within the dendritic spine that is essential for late LTP maintenance in vivo. Neuron 38:447-460.

Furukawa K, Smith-Swintosky VL, Mattson MP (1995) Evidence that actin depolymerization protects hippocampal neurons against excitotoxicity by stabilizing $\left[\mathrm{Ca}^{2+}\right]$ i. Exp Neurol 133:153-163.

Gehler S, Shaw A, Sarmiere P, Bamburg J, Letourneau P (2004) Brainderived neurotrophic factor regulation of retinal growth cone filopodial dynamics is mediated through actin depolymerizing factor/cofilin. J Neurosci 24:10741-10749.

Godfraind J, Reyniers E, De Boulle K, D’Hooge R, De Deyn P, Bakker C, Oostra B, Kooy R, Willems P (1996) Long-term potentiation in the hippocampus of fragile X knockout mice. Am J Med Genet 64:246-251.

Grossman A, Elisseou N, McKinney B, Greenough W (2006) Hippocampal pyramidal cells in adult Fmrl knockout mice exhibit an immatureappearing profile of dendritic spines. Brain Res 1084:158-164.

Hinton V, Brown W, Wisniewski K, Rudelli R (1991) Analysis of neocortex in three males with fragile X syndrome. Am J Med Genet 41:289-294.

Irwin S, Patel B, Idupulapati M, Harris J, Crisostomo R, Larsen B, Kooy F, Willems P, Cras P, Kozlowski P, Swain R, Weiler I, Greenough W (2001) Abnormal dendritic spine characteristics in the temporal and visual cortices of patients with fragile-X syndrome: a quantitative examination. Am J Med Genet 98:161-167.

Irwin S, Idupulapati M, Gilbert M, Harris J, Chakravarti A, Rogers E, Crisostomo R, Larsen B, Mehta A, Alacantara C, Patel B, Swain R, Weiler I, Oostra B, Greenough W (2002) Dendritic spine and dendritic field characteristics on layer $\mathrm{V}$ pyramidal neurons in the visual cortex of fragile- $\mathrm{X}$ knockout mice. Am J Med Genet 111:140-146.

Jain AK (1984) Fundamentals of digital image processing. Englewood Cliffs, NJ: Prentice Hall.

Jancsik V, Hajos F (1998) Differential distribution of dystrophin in postsynaptic densities of spine synapses. NeuroReport 9:2249-2251.

Kang HJ, Welcher AA, Shelton D, Schuman EM (1997) Neurotrophins and time: different roles for TrkB signaling in hippocampal long-term potentiation. Neuron 19:653-664.

Kelleher III RJ, Govindarajan A, Jung HY, Kang H, Tonegawa S (2004) Translational control by MAPK signaling in long-term synaptic plasticity and memory. Cell 116:467-479.

Korte M, Carroll P, Wolf E, Brem G, Thoenen H, Bonhoeffer T (1995) Hippocampal long-term potentiation is impaired in mice lacking brainderived neurotrophic factor. Proc Natl Acad Sci USA 92:8856-8860.

Kramár E, Lynch G (2003) Developmental and regional differences in the consolidation of long-term potentiation. Neuroscience 118:387-398.

Kramár E, Lin B, Lin C, Arai A, Gall C, Lynch G (2004) A novel mechanism for the facilitation of theta-induced long-term potentiation by brainderived neurotrophic factor. J Neurosci 24:5151-5161.
Kramár E, Lin B, Rex C, Gall C, Lynch G (2006) Integrin-driven actin polymerization consolidates long-term potentiation. Proc Natl Acad Sci USA 103:5579-5584.

Larson J, Lynch G (1986) Induction of synaptic potentiation in hippocampus by patterned stimulation involves two events. Science 232:985-988.

Larson J, Lynch G (1989) Theta pattern stimulation and the induction of LTP: the sequence in which synapses are stimulated determines the degree to which they potentiate. Brain Res 489:49-58.

Larson J, Lynch G (1998) Role of N-methyl-D-aspartate receptors in the induction of synaptic potentiation by burst stimulation patterned after the hippocampal theta-rhythm. Brain Res 441:111-118.

Larson J, Wong D, Lynch G (1986) Patterned stimulation at the theta frequency is optimal for the induction of hippocampal long-term potentiation. Brain Res 368:347-350.

Larson J, Jessen R, Kim D, Fine A, du Hoffmann J (2005) Age-dependent and selective impairment of long-term potentiation in the anterior piriform cortex of mice lacking the fragile $\mathrm{X}$ mental retardation protein. J Neurosci 25:9460-9469.

Lauterborn JC, Lynch G, Vanderklish P, Avai A, Gall CM (2000) Positive modulation of AMPA receptors increases neurotrophin expression by hippocampal and cortical neurons. J Neurosci 20:8-21.

Lee K, Schottler F, Oliver M, Lynch G (1980) Brief bursts of high-frequency stimulation produce two types of structural changes in rat hippocampus. J Neurophysiol 44:247-258.

Li J, Pelletier MR, Perez Velazquez JL, Carlen PL (2002) Reduced cortical synaptic plasticity and GluR1 expression associated with fragile X mental retardation protein deficiency. Mol Cell Neurosci 19:138-151.

Lin B, Kramár E, Bi X, Brucher F, Gall C, Lynch G (2005a) Theta stimulation polymerizes actin in dendritic spines of hippocampus. J Neurosci 25:2062-2069.

Lin CY, Lynch G, Gall C (2005b) AMPA receptor stimulation increases $\alpha 5 \beta 1$ integrin surface expression, adhesive function and signaling. J Neurochem 94:531-546.

Lund R (1978) Development and plasticity of the brain. New York: Oxford UP.

Lynch G, Rex C, Gall C (2007a) LTP consolidation: substrates, explanatory power, and functional significance. Neuropharmacology 52:12-23.

Lynch G, Kramár EA, Rex CS, Jia Y, Chappas D, Gall CM, Simmons DA (2007b) Brain-derived neurotrophic factor restores synaptic plasticity in a knock-in mouse model of Huntington's disease. J Neurosci 27:4424-4434.

Marin-Padilla M (1972) Structural abnormalities of the cerebral cortex in human chromosomal aberrations. Brain Res 44:625-629.

Marin-Padilla M (1974) Structural organization of the cerebral cortex (motor area) in human chromosomal aberrations. A Golgi study. Brain Res 66:375-391.

Meng Y, Zhang Y, Tregoubov V, Falls D, Jia Z (2003) Regulation of spine morphology and synaptic function by LIMK and the actin cytoskeleton. Rev Neurosci 14:233-240.

Meredith RM, Holmgren CD, Weidum M, Burnashev N, Mansvelder HD (2007) Increased threshold for spike-timing-dependent plasticity is caused by unreliable calcium signaling in mice lacking fragile $\mathrm{X}$ gene FMR1. Neuron 54:627-638.

Michalski B, Fahnestock M (2003) Pro-brain-derived neurotrophic factor is decreased in parietal cortex in Alzheimer's disease. Mol Brain Res 111:148-154.

Miyamoto Y, Yamauchi J, Tanoue A, Wu C, Mobley W (2006) TrkB binds and tyrosine-phosphorylates Tiam1, leading to activation of Rac1 and induction of changes in cellular morphology. Proc Natl Acad Sci USA 103:10444-10449.

Miyashiro K, Beckel-Mitchener A, Purk T, Becker K, Barret T, Liu L, Carbonetto S, Weiler I, Greenough W, Eberwine J (2003) RNA cargoes associating with FMRP reveal deficits in cellular functioning in Fmrl null mice. Neuron 37:417-431.

Mott D, Lewis D (1991) Facilitation of the induction of long-term potentiation by GABAB receptors. Science 252:1718-1720.

Mowla S, Farhadi H, Pareek S, Atwal J, Morris S, Seidah N, Murphy R (2001) Biosynthesis and post-translational processing of the precursor to brainderived neurotrophic factor. J Biol Chem 276:12660-12666.

Muddashetty R, Kelić S, Gross C, Xu M, Bassell G (2007) Dysregulated metabotropic glutamate receptor-dependent translation of AMPA recep- 
tor and postsynaptic density-95 mRNAs at synapses in a mouse model of fragile X syndrome. J Neurosci 27:5338-5348.

Nawa H, Carnahan J, Gall C (1995) BDNF protein measured by a novel enzyme immunoassay in normal brain and after seizure: partial disagreement with mRNA levels. Eur J Neurosci 7:1527-1535.

Oostra B, Hoogeveen A (1997) Animal model for fragile X syndrome. Ann Med 29:563-567.

Otto T, Eichenbaum H, Wiener SI, Wible CG (1991) Learning-related patterns of CA1 spike trains parallel stimulation parameters optimal for inducing hippocampal long-term potentiation. Hippocampus 1:181-192.

Ozdinler P, Erzurumlu R (2001) Regulation of neurotrophin-induced axonal responses via Rho GTPases. J Comp Neurol 438:377-387.

Pang P, Teng H, Zaitsev E, Woo N, Sakata K, Zhen S, Teng K, Yung W, Hempstead B, Lu B (2004) Cleavage of proBDNF by tPA/plasmin is essential for long-term hippocampal plasticity. Science 306:487-491.

Paradee W, Melikian HE, Rasmussen DL, Kenneson A, Conn PJ, Warren ST (1999) Fragile X mouse: strain effects of knockout phenotype and evidence suggesting deficient amygdala function. Neuroscience 94:185-192.

Park M, Salgado JM, Ostroff L, Helton TD, Robinson CG, Harris KM, Ehlers MD (2006) Plasticity-induced growth of dendritic spines by exocytic trafficking from recycling endosomes. Neuron 52:817-830.

Patterson SL, Abel T, Deuel TA, Martin KC, Rose JC, Kandel ER (1996) Recombinant BDNF rescues deficits in basal synaptic transmission and hippocampal LTP in BDNF knockout mice. Neuron 16:1137-1145.

Pollak D, Herkner K, Hoeger H, Lubec G (2005) Behavioral testing upregulates pCaMKII, BDNF, PSD-95 and egr-1 in hippocampus of FVB/N mice. Behav Brain Res 163:128-135.

Racz B, Weinberg R (2006) Spatial organization of cofilin in dendritic spines. Neuroscience 138:447-456.

Reeve S, Bassetto L, Genova G, Kleyner Y, Leyssen M, Jackson F, Hassan B (2005) The Drosophila fragile X mental retardation protein controls actin dynamics by directly regulating profilin in the brain. Curr Biol 15:1156-1163.

Rex C, Kramár E, Colgin L, Lin B, Gall C, Lynch G (2005) Long-term potentiation is impaired in middle-aged rats: regional specificity and reversal by adenosine receptor antagonists. J Neurosci 25:5956-5966.

Rex CS, Lauterborn JC, Lin CY, Kramár EA, Rogers GA, Gall CM, Lynch G (2006) Restoration of long-term potentiation in middle-aged hippocampus after induction of brain-derived neurotrophic factor. J Neurophysiol 96:677-685.

Rex CS, Lin CY, Kramár EA, Chen LY, Gall CM, Lynch G (2007) Brainderived neurotrophic factor promotes long-term potentiation-related cytoskeletal changes in adult hippocampus. J Neurosci 27:3017-3029.

Reymann KG, Frey JU (2007) The late maintenance of hippocampal LTP: requirements, phases, "synaptic tagging," "late-associativity" and implications. Neuropharmacology 52:24-40.

Rosenmund C, Westbrook G (1993) Calcium-induced actin depolymerization reduces NMDA channel activity. Neuron 10:805-814.

Rudelli R, Brown W, Wisniewski K, Jenkins E, Laure-Kamionowska M, Connell F, Wisniewski H (1985) Adult fragile X syndrome. Cliniconeuropathologic findings. Acta Neuropathol 67:289-295.

Sano K, Nanba H, Tabuchi A, Tsuhiya T, Tsuda M (1996) BDNF gene can be activated by $\mathrm{CA}^{2+}$ signals without involvement of de novo AP-1 synthesis. Biochem Biophys Res Commun 229:788-793.

Siman R, Ahdoot M, Lynch G (1987) Ontogeny, compartmentation, and turnover of spectrin isoforms in rat central neurons. J Neurosci 7:55-64.
Staubli U, Perez Y, Xu F, Rogers G, Ingvar M, Stone-Elander S, Lynch G (1994) Centrally active modulators of glutamate (AMPA) receptors facilitate the induction of LTP in vivo. Proc Natl Acad Sci USA 91:11158-11162.

Teng H, Teng K, Lee R, Wright S, Tevar S, Almeida R, Kermani P, Torkin R, Chen Z-Y, Lee F, Kraemer R, Nykjaer A, Hempstead B (2005) ProBDNF induces neuronal apoptosis via activation of a receptor complex of p75NTR and sortilin. J Neurosci 25:5455-5463.

The Dutch-Belgian Fragile X Consortium (1994) FMR1 knockout mice: a model to study fragile $\mathrm{X}$ mental retardation. Cell 78:23-33.

Todd P, Malter J (2002) Fragile X mental retardation protein in plasticity and disease. J Neurosci Res 70:623-630.

Tombaugh G, Rowe W, Chow A, Michael T, Rose G (2002) Thetafrequency synaptic potentiation in CA1 in vitro distinguishes cognitively impaired from unimpaired aged Fisher 344 rats. J Neurosci 22:9932-9940.

Toni N, Buchs P, Nikonenko I, Povilaitite P, Parisi L, Muller D (2001) Remodeling of synaptic membranes after induction of long-term potentiation. J Neurosci 21:6245-6251.

Walsh M, Kuruc N (1992) The postsynaptic density: constituent and associated proteins characterized by electrophoresis, immunoblotting, and peptide sequencing. J Neurochem 59:667-678.

Weiler I, Spangler C, Klintsova A, Grossman A, Kim S, Bertaina-Anglade V, Khaliq H, de Vries F, Lambers F, Hatia F, Base C, Greenough W (2004) Fragile X mental retardation protein is necessary for neurotransmitteractivated protein translation at synapses. Proc Natl Acad Sci USA 101:17504-17509.

Woo NH, Nguyen PV (2003) Protein synthesis is required for synaptic immunity to depotentiation. J Neurosci 23:1125-1132.

Wyneken U, Smalla K, Marengo J, Soto D, de la Cerda A, Tischmeyer W, Grimm R, Boeckers T, Wolf G, Orrego F, Gundelfinger E (2001) Kainate-induced seizures alter protein composition and $\mathrm{N}$-methyl-Daspartate receptor function of rat forebrain postsynaptic densities. Neuroscience 102:65-74.

Wyszynski M, Kharazia V, Shanghvi R, Rao A, Beggs A, Craig A, Weinberg R, Sheng M (1998) Differential regional expression and ultrastructural localization of alpha-actinin-2, a putative NMDA receptor-anchoring protein, in rat brain. J Neurosci 18:1383-1392.

Zalfa F, Giorgi M, Primerano B, Moro A, Di Penta A, Reis S, Oostra B, Bagni C (2003) The fragile X syndrome protein FMRP associates with BC1 RNA and regulates the translation of specific mRNAs at synapses. Cell 112:317-327.

Zalfa F, Eleuteri B, Dickson K, Mercaldo V, De Rubeis S, di Penta A, Tabolacci E, Chiurazzi P, Neri G, Grant S, Bagni C (2007) A new function for the fragile X mental retardation protein in regulation of PSD-95 mRNA stability. Nat Neurosci 10:578-587.

Zhao M, Toyoda H, Ko S, Ding H, Wu L, Zhuo M (2005) Deficits in trace fear memory and long-term potentiation in a mouse model for fragile $\mathrm{X}$ syndrome. J Neurosci 25:7385-7392.

Zhou Q, Homma K, Poo M (2004a) Shrinkage of dendritic spines associated with long-term depression of hippocampal synapses. Neuron 44:749-757.

Zhou X, Song X, Zhong J, Barati S, Zhou F, Johnson S (2004b) Distribution and localization of pro-brain-derived neurotrophic factor-like immunoreactivity in the peripheral and central nervous system of the adult rat. J Neurochem 91:704-715. 